Article

\title{
Gas phase dehydration of glycerol to acrolein catalyzed by zirconium phosphate
}

\author{
Huimei Gan, Xiuge Zhao, Baoning Song, Li Guo, Ran Zhang, Chen Chen, Jizhong Chen, Wenwen Zhu, \\ Zhenshan Hou* \\ Key Laboratory for Advanced Materials, Research Institute of Industrial Catalysis, East China University of Science and Technology, Shanghai 200237, \\ China
}

\section{A R T I C L E I N F 0}

\section{Article history:}

Received 20 December 2013

Accepted 20 February 2014

Published 20 July 2014

\section{Keywords:}

Glycerol

Dehydration

Acrolein

Zirconium phosphate

Acidity

\begin{abstract}
A B S T R A C T
Zirconium phosphates were prepared by precipitation, hydrothermal synthesis, and impregnation methods and were characterized by X-ray diffraction, thermogravimetric analysis, nitrogen adsorption, Fourier transform infrared spectroscopy, and Hammett indicators. The different preparation methods have crucial effects on the texture and surface acidity of the zirconium phosphates. The zirconium phosphates were employed as catalysts for the gas phase dehydration of glycerol under mild reaction conditions. The zirconium phosphates from the precipitation method afforded the highest activity with the complete conversion of glycerol, $81 \%$ selectivity to acrolein, and no obvious deactivation over $24 \mathrm{~h}$. Surface acidic sites played an important role in the activity, selectivity to acrolein, and life of catalysts.
\end{abstract}

(C) 2014, Dalian Institute of Chemical Physics, Chinese Academy of Sciences. Published by Elsevier B.V. All rights reserved.

\section{Introduction}

Biodiesel has received much attention and has a rapid annual increase in its worldwide production [1] because it is environmentally benign and renewable. It is a promising alternative resource for diesel [2]. However, the production of biodiesel leads to $10 \%$ glycerol byproduct, and hence, to increase the capacity for biodiesel, the glycerol market will need to expand. Thus, the question arises for a cost-effective and efficient use of a glycerol surplus. Unfortunately, raw glycerol is not usable in conventional energy production plants [3]. Therefore, using glycerol for the synthesis of value-added chemicals, such as acrolein, hydroxyacetone, 1,3-propylene glycol, lactic acid, and dihydroxyacetone, is of great industrial importance.

Acrolein, which is an important intermediate used for the production of acrylic acid esters, adhesive, polymers, and detergents, is produced by the oxidation of propylene over a $\mathrm{Bi} / \mathrm{Mo}$ mixed oxide catalyst in the current commercial catalytic petrochemical process [4]. It is apparent that catalytic dehydration of glycerol to acrolein can provide a more cost-effective and sustainable alternative route (Scheme 1), and it has become a research hotspot in recent years [5]. Some research has been devoted to glycerol dehydration in near and supercritical water [6-8]. Taking into account catalyst separation, recovery, and apparatus corrosion, it is preferable to carry out the dehydration reactions in the gas phase over a solid acid catalyst. In the last decade, supported heteropolyacids [9-13], supported $\mathrm{WO}_{3}[14,15], \mathrm{Zr}-\mathrm{Nb}$ mixed oxides [16], zeolites [17,18], sulfonic acid-functionalized SBA-15 [19], and metal phosphates [20-24] have been shown to exhibit high catalytic activities. High acro-

\footnotetext{
* Corresponding author. Tel: +86-21-64251686; Fax: +86-21-64253372; E-mail: houzhenshan@ecust.edu.cn This work was supported by the National Natural Science Foundation of China (U1179302, 21373082, 21073058), the Specialized Research Fund for the Doctoral Program of Higher Education (20100074110014), and the Fundamental Research Funds for the Central Universities. DOI: 10.1016/S1872-2067(14)60057-7 | http://www.sciencedirect.com/science/journal/18722067 | Chin. J. Catal., Vol. 35, No. 7, July 2014
} 


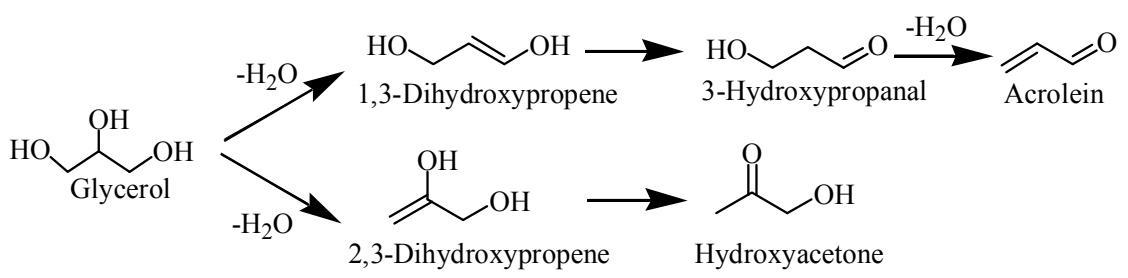

Scheme 1. Formation of the products of glycerol dehydration over acid catalysts.

lein selectivity (90-100 mol\%) along with complete glycerol conversion was reported for rubidium- and caesium-doped silicotungstic acid catalysts supported on alumina [25]. Moreover, it was found that the catalytic efficiency for the formation of acrolein was enhanced at medium acidity strength $\left(-8.2<H_{0}\right.$ $\leq-3.0)$ [26], while strong acid sites $\left(H_{0} \leq-8.2\right)$ resulted in a lower acrolein selectivity ( $40-50 \mathrm{~mol} \%$ ) due to severe coke deposition in the reaction, and weak acid sites on the catalyst surface $\left(-3.0<H_{0} \leq+6.8\right)$ were not selective for acrolein production. Another work pointed out that Brönsted acid sites were more active and selective than Lewis acid sites [6]. The generation of acrolein was initiated by the protonation of the secondary hydroxyl group of the glycerol molecule by a proton of a Brönsted acid site. Subsequent steps involve the elimination of $\mathrm{H}_{3} \mathrm{O}^{+}$to give 1,3-dihydroxypropene and its tautomerization to 3-hydroxypropanal. The latter underwent further acid-catalyzed dehydration to yield acrolein. Lewis acid sites were more prone to interact with a terminal hydroxyl group rather than the internal one, and then concerted transfer of the terminal $\mathrm{OH}$ group of glycerol to the $\mathrm{M}$ sites (Lewis acid sites) and migration of the $\mathrm{H}^{+}$from the internal carbon atom to the bridging 0 atom of the oxide gives 2,3-dihydroxypropene together with the hydrated active site on the catalyst [27].

Nevertheless, the production of acrolein from glycerol has not been commercialized because the present catalysts have the disadvantages of low thermal stability, low sedimentation ability, less water tolerant ability, and low catalytic stability. Thus the search for a more cost-effective catalyst for the dehydration of glycerol and the development of better process alternatives still attract attention. As is known, only a few solid acids exhibit acceptable activity and stability when water participates as a reactant or product. Here, metal phosphate is one class of the most important heterogeneous solid acid catalyst that is attractive for esterification, dehydration, and hydrolysis reactions $[28,29]$. The majority of these catalysts have high sedimentation ability, and this property can prevent the solid acid from dissolving in water, which otherwise would cause catalyst loss or contamination of the reaction mixture. Among the metal phosphate catalysts used for glycerol dehydration, although the complete conversion of glycerol can be achieved easily, the selectivity to acrolein and the stability of the catalyst still remain a challenge. Zirconium phosphate is a very important metal phosphate that has extremely high thermal stability and water-tolerant ability, and it has been utilized for oxidation reaction [30] and glucose dehydration in the presence of excess water [31,32], but it has not been well investigated in the dehydration of glycerol. In this work, we performed a systematic characterization of a series of zirconium phosphates prepared by precipitation, hydrothermal synthesis, and impregnation methods. Subsequently, the zirconium phosphates were utilized for the gas phase dehydration of glycerol in a fixed-bed reactor. From the catalyst characterization and evaluation of catalytic activity, the effects of catalyst texture and acidic sites on catalytic performance were discussed.

\section{Experimental}

\subsection{Materials}

Zirconium oxychloride, ammonium dihydrogen phosphate, glycerol, silver nitrate, phosphoric acid, $n$-butylamine, anthraquinone $\left(\mathrm{p} K_{\mathrm{a}}=-8.2\right)$, and neutral red $\left(\mathrm{p} K_{\mathrm{a}}=+6.8\right)$ were purchased from Sinopharm Chemical Reagent Co. Ltd. (Shanghai, China). Dicinnamalacetone $\left(\mathrm{p} K_{\mathrm{a}}=-3.0\right)$ was supplied by Aldrich. High purity $\mathrm{N}_{2}$ was supplied by Shangnong Gas Factory. Distilled water used in this work was produced by our own laboratory. All other chemicals (analytical grade) were from Sinopharm Chemical Reagent Co. Ltd. and used as received without any further purification.

\subsection{Catalyst preparation}

The zirconium phosphates were prepared by three different methods. First, a precipitation method was used to obtain zirconium phosphate. Briefly, an aqueous solution of $\mathrm{NH}_{4} \mathrm{H}_{2} \mathrm{PO}_{4}$ $(1.0 \mathrm{~mol} / \mathrm{L}, 64 \mathrm{ml})$ was added dropwise to an aqueous solution of $\mathrm{ZrOCl}_{2} \cdot 8 \mathrm{H}_{2} \mathrm{O}(1.0 \mathrm{~mol} / \mathrm{L}, 32 \mathrm{ml})$ at a molar ratio of $\mathrm{P} / \mathrm{Zr}=2$. The mixture was stirred overnight at room temperature, then filtered, and washed with deionized water until the $\mathrm{pH}$ of the filtrate reached 6 and no $\mathrm{Cl}^{-}$was detected by an acidic $\mathrm{AgNO}_{3}$ solution. The material obtained was dried for $12 \mathrm{~h}$ at $100{ }^{\circ} \mathrm{C}$, followed by calcination at different temperatures for $4 \mathrm{~h}$ in a muffle furnace prior to reaction. The resulting material was named as $\mathrm{ZrP}-\mathrm{T}$, where $T$ represented the calcination temperature. The elemental analysis demonstrated that the molar ratio of phosphate to zirconia was 1.54 .

Second, a hydrothermal method was carried out to prepare zirconium phosphate. A solution of zirconyl chloride $(1 \mathrm{~mol} / \mathrm{L}$, $20 \mathrm{ml}$ ), which had been previously prepared by dissolving zirconyl chloride powder in $1 \mathrm{~mol} / \mathrm{L} \mathrm{HCl}$, was added to a $\mathrm{H}_{3} \mathrm{PO}_{4}$ aqueous solution ( $4 \mathrm{~mol} / \mathrm{L}, 10 \mathrm{ml}$ ), and then the mixture was stirred overnight at room temperature. The white precipitate was collected by filtration, washed with deionized water, then reslurried with $12 \mathrm{~mol} / \mathrm{L} \mathrm{H}_{3} \mathrm{PO}_{4}$, and heated to $150^{\circ} \mathrm{C}$ in an autoclave for $3 \mathrm{~d}$. The resulting product was collected by stirring vigorous the product with deionized water and centrifuging until the $\mathrm{pH}$ of the supernatant reached 5 to remove excess 
$\mathrm{H}_{3} \mathrm{PO}_{4}$. After drying for $12 \mathrm{~h}$ at $100{ }^{\circ} \mathrm{C}$, the product was calcined at $400{ }^{\circ} \mathrm{C}$ for $4 \mathrm{~h}$. This was named as ZrP-HT. The elemental analysis by inductively coupled plasma-Auger electron spectroscopy demonstrated that the molar ratio of phosphate to zirconia was 2.06 .

Third, for the catalyst prepared by impregnation, $\mathrm{ZrO}_{2}$ was prepared at room temperature by a simple process [33]. Zirconyl chloride $(0.035 \mathrm{~mol})$ was dissolved in $35 \mathrm{ml}$ of deionized water and stirred magnetically for $5 \mathrm{~min}$, and then aqueous ammonia (25 wt\%) was slowly added in with rigorous stirring until the $\mathrm{pH}$ was 7 . The resulting precipitate was filtered and washed repeatedly with deionized water until no $\mathrm{Cl}^{-}$was present (detection by acidic $\mathrm{AgNO}_{3}$ solution). The white precipitate was dried at $110{ }^{\circ} \mathrm{C}$ for $12 \mathrm{~h}$, and then calcined at $400^{\circ} \mathrm{C}$ for $4 \mathrm{~h}$ to obtain $\mathrm{ZrO}_{2}$. Then $\mathrm{ZrO}_{2}$ was impregnated with a solution of $\mathrm{H}_{3} \mathrm{PO}_{4}$ by an incipient wetness method at a molar ratio of $\mathrm{P} / \mathrm{Zr}$ $=2: 1$. The mixture was stirred overnight at room temperature, which was followed by drying at $100{ }^{\circ} \mathrm{C}$ for $12 \mathrm{~h}$. The product was calcined at $400{ }^{\circ} \mathrm{C}$ for $4 \mathrm{~h}$. This was named as $\mathrm{P} / \mathrm{ZrO}_{2}$. The calcined catalysts were pressed, crushed, and sieved to 20-40 mesh prior to reaction.

\subsection{Catalyst characterization}

X-ray diffraction (XRD) analysis of the fresh and used catalysts were performed in the $2 \theta$ range of $10^{\circ}-80^{\circ}$ on an Rigaku D/MAX $2550 \mathrm{VB} / \mathrm{PC}$ instrument using a graphite crystal as monochromator. The textural properties from $\mathrm{N}_{2}$ adsorption isotherms were obtained on a Quantachrome NOVA 2200e equipment. The surface area was obtained from the isotherms in the relative pressure range of $0.0-0.35$. Pore volume was determined at $p / p_{0}$ of 0.99 . The inductively coupled plasma-Auger electron spectroscopy (ICP-AES) analysis was performed on a Varian ICP-710ES instrument. The sample was first treated with a hydrofluoric acid and nitric acid solution, and then was heated to $60^{\circ} \mathrm{C}$ in an oil bath to remove hydrofluoric acid, followed by dissolving with water. Fourier transform infrared (FT-IR) spectra of the samples were obtained on a Nicolet Fourier transform infrared spectrometer (Magna 550) in the range of 4000-400 $\mathrm{cm}^{-1}$. Thermal analysis of the catalysts was conducted on a Netzsch STA 449C thermal analyzer. The sample was placed in an $\mathrm{Al}_{2} \mathrm{O}_{3}$ crucible and heated in flowing air $(200 \mathrm{ml} / \mathrm{min})$ from 50 to $800^{\circ} \mathrm{C}$ at a rate of $10^{\circ} \mathrm{C} / \mathrm{min}$. The sample was dried overnight at $100{ }^{\circ} \mathrm{C}$ prior to the measurement. The determination of the acidic properties of the solid acid catalysts used the $n$-butylamine titration method using various Hammett indicators, including anthraquinone $\left(\mathrm{p} K_{\mathrm{a}}=\right.$ $-8.2)$, dicinnamalacetone $\left(\mathrm{p} K_{\mathrm{a}}=-3.0\right)$ and neutral $\operatorname{red}\left(\mathrm{p} K_{\mathrm{a}}=\right.$ +6.8). The acid strength was expressed by the Hammett acidity function $\left(H_{0}\right)$ scaled by the $\mathrm{p} K_{\mathrm{a}}$ values of the indicators. Before the measurement, the sample was grinded to 100-120 mesh.

\subsection{Catalytic reaction}

The dehydration of glycerol was carried out in a vertical fixed-bed stainless steel reactor ( $1.1 \mathrm{~mm}$ i.d., length $55 \mathrm{~cm}$ ). A constant weight $(0.5 \mathrm{~g})$ of catalyst was sandwiched in the mid- dle of the reactor with quartz wool and quartz sand for supporting the catalyst and evaporation of the reactants. The temperature was controlled by a thermocouple placed in the middle of the catalyst bed. Prior to the reaction, catalyst was pretreated at the reaction temperature $\left(315^{\circ} \mathrm{C}\right)$ for $1.5 \mathrm{~h}$ with high purity $\mathrm{N}_{2}(0.1 \mathrm{MPa}, 30 \mathrm{ml} / \mathrm{min})$. The feedstock, an aqueous solution containing $10 \mathrm{wt} \%$ glycerol, was then pumped into the reactor $(0.04 \mathrm{ml} / \mathrm{min})$ and driven through the catalyst bed by nitrogen. The reaction products were condensed in a cryogenic cooling system and collected every two hours for offline analysis using a GC 112A gas chromatograph equipped with an FFAP capillary column (30 m long, $0.32 \mathrm{~mm}$ i.d., $0.33 \mu \mathrm{m}$ film thickness) and an Agilent 6890/5973 GC-MS System equipped with a HP-5MS column (30 m long, $0.25 \mathrm{~mm}$ i.d., $0.25 \mu \mathrm{m}$ film thickness) and flame ionization detector (FID). Volatile compounds that were not retained in the cold trap were absorbed in ethanol and also analyzed by offline GC. For quantitative measurements, $n$-propanol was used as the internal standard. The conversion of glycerol and yield towards products were calculated as follows: Conversion $=\left(n_{1} / n_{0}\right) \times 100 \%$ and Yield $=$ $\left(n_{\mathrm{p}} / n_{0}\right) \times 100 \%$, where $n_{0}$ is the mole of carbon in the glycerol fed, $n_{1}$ is the mole of carbon in glycerol converted, and $n_{\mathrm{p}}$ is the mole of carbon in an identified product. The carbon balance was estimated as the percentage of the reacted carbon atoms found in the organic products.

\section{Results and discussion}

\subsection{Catalyst characterization}

Figure 1(a) shows the XRD patterns of the $\mathrm{ZrO}_{2}, \mathrm{P} / \mathrm{ZrO}_{2}$, and $\mathrm{ZrP}$-HT catalysts. The diffraction peaks of $\mathrm{ZrO}_{2}$ were observed at $30.3^{\circ}, 35^{\circ}$ and $50.2^{\circ}$ which were attributed to the (111), (200), and (220) lattice planes, respectively, which represented the structure of the tetragonal $\mathrm{ZrO}_{2}$ phase. The hydrothermally synthesized ZrP-HT showed typical diffraction peaks of zirconium phosphate, and the peaks were sharp and narrow, indicating that the sample was highly crystalline. The three main strong diffraction peaks at $11.7^{\circ}, 19.7^{\circ}$, and $24.9^{\circ}$ corresponded to the characteristic diffraction peaks of $\alpha-\operatorname{Zr}\left(\mathrm{HPO}_{4}\right)_{2} \cdot \mathrm{H}_{2} \mathrm{O}$ at (002), (110), and (112), respectively [34]. In addition, $\mathrm{P} / \mathrm{ZrO}_{2}$ showed the characteristic diffraction peaks of both zirconium phosphate and zirconia, indicating that this material contained the two phases of zirconia and zirconium phosphate. The XRD patterns of the calcined ZrP-T samples are shown in Fig. 1(b). No distinct diffraction pattern was detected for the samples even after calcination at $700{ }^{\circ} \mathrm{C}$, confirming the high thermal stability of synthesized $\mathrm{ZrP}$ [35]. The presence of two broad peaks in the ranges of $10^{\circ}-40^{\circ}$ and $40^{\circ}-70^{\circ}$ indicated their amorphous nature [36].

The textural properties of the samples are shown in Table 1. Obviously, the surface area and pore volume were significantly decreased after $\mathrm{ZrO}_{2}$ was impregnated with phosphoric acid $\left(\mathrm{P} / \mathrm{ZrO}_{2}\right)$. The loss of surface area and pore volume can be ascribed to the formation of polymeric phosphates species inside the $\mathrm{ZrO}_{2}$ channels and on its outer surface [37]. ZrP-HT also had a very low BET surface area, which was only $20 \mathrm{~m}^{2} / \mathrm{g}$. In 


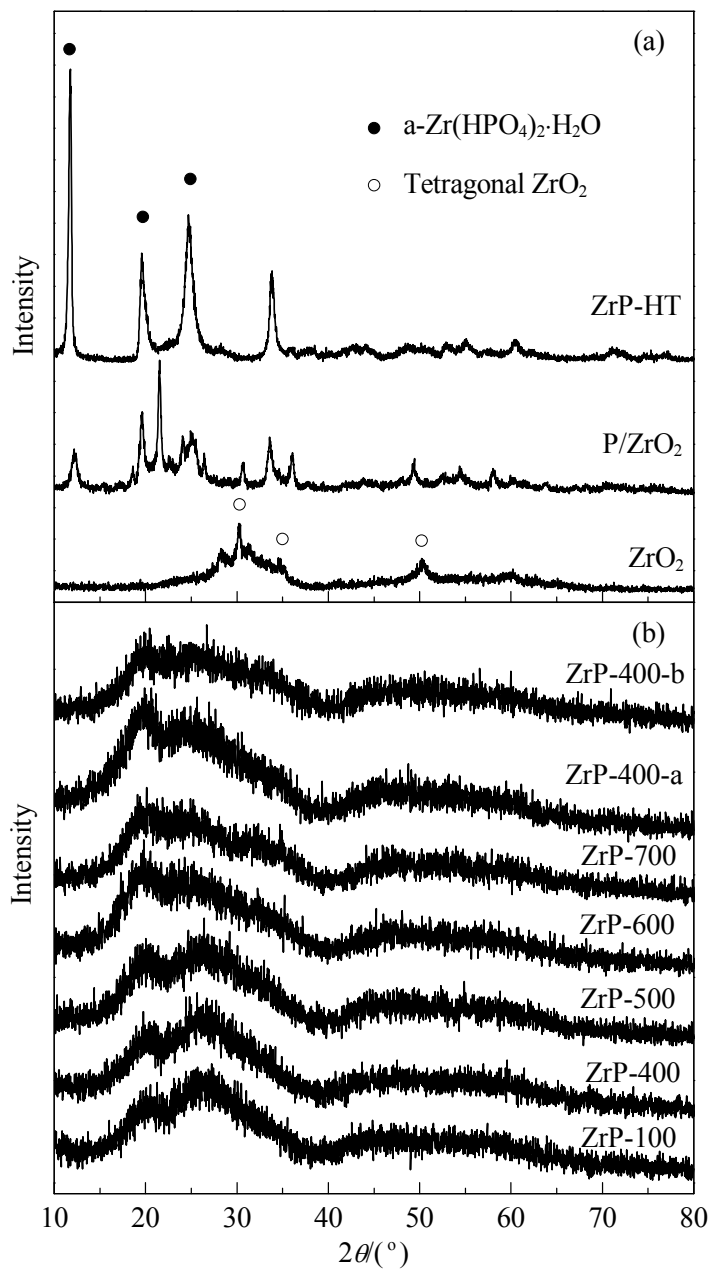

Fig. 1. (a) XRD patterns of the $\mathrm{ZrO}_{2}, \mathrm{P} / \mathrm{ZrO}_{2}$, and $\mathrm{ZrP}-\mathrm{HT}$ catalysts; (b) XRD patterns of the fresh $\mathrm{ZrP}-\mathrm{T}$ catalysts, as well as the $\mathrm{ZrP}-400$ catalyst after reaction for $24 \mathrm{~h}$ (ZrP-400-a) and the ZrP-400 catalyst after reaction for $48 \mathrm{~h}$ then calcined at $500^{\circ} \mathrm{C}$ for $4 \mathrm{~h}(\mathrm{ZrP}-400-\mathrm{b})$.

contrast, ZrP-T had a high BET surface area at a low calcination temperature $\left(122 \mathrm{~m}^{2} / \mathrm{g}\right)$ and showed a clear trend where the BET surface area decreased from $122 \mathrm{~m}^{2} / \mathrm{g}$ to $44 \mathrm{~m}^{2} / \mathrm{g}$ as the calcination temperature increased from 100 to $700{ }^{\circ} \mathrm{C}$. Thus, the specific surface area of the zirconium phosphates synthesized by the precipitation method was considerably larger than that of the samples obtained from the impregnation and hydrothermal methods.

The TG patterns of ZrP-100 and ZrP-400 from 50 to $800{ }^{\circ} \mathrm{C}$

Table 1

Specific surface area and pore diameter of the catalysts determined by nitrogen adsorption before and after glycerol dehydration for $24 \mathrm{~h}$.

\begin{tabular}{lcccc}
\hline Catalyst & $\begin{array}{c}\text { BET surface } \\
\text { area }\left(\mathrm{m}^{2} / \mathrm{g}\right)\end{array}$ & $\begin{array}{c}\text { Pore volume } \\
\left(\mathrm{cm}^{3} / \mathrm{g}\right)\end{array}$ & \multicolumn{2}{c}{ Average pore diameter $(\mathrm{nm})$} \\
\cline { 5 - 5 } $\mathrm{ZrO}_{2}$ & 75 & 0.07 & 1.7 & 1.7 \\
$\mathrm{P}_{\mathrm{ZrO}}$ & 4 & 0.01 & 1.5 & 1.7 \\
$\mathrm{ZrP}-\mathrm{HT}$ & 20 & 0.09 & 2.8 & 1.9 \\
$\mathrm{ZrP}-100$ & 122 & 0.24 & 2.7 & 3.5 \\
$\mathrm{ZrP}-400$ & 101 & 0.22 & 1.7 & 1.7 \\
$\mathrm{ZrP}-500$ & 92 & 0.20 & 1.7 & 1.7 \\
$\mathrm{ZrP}-600$ & 79 & 0.16 & 2.4 & 1.7 \\
ZrP-700 & 44 & 0.14 & 2.1 & 1.9 \\
\hline
\end{tabular}

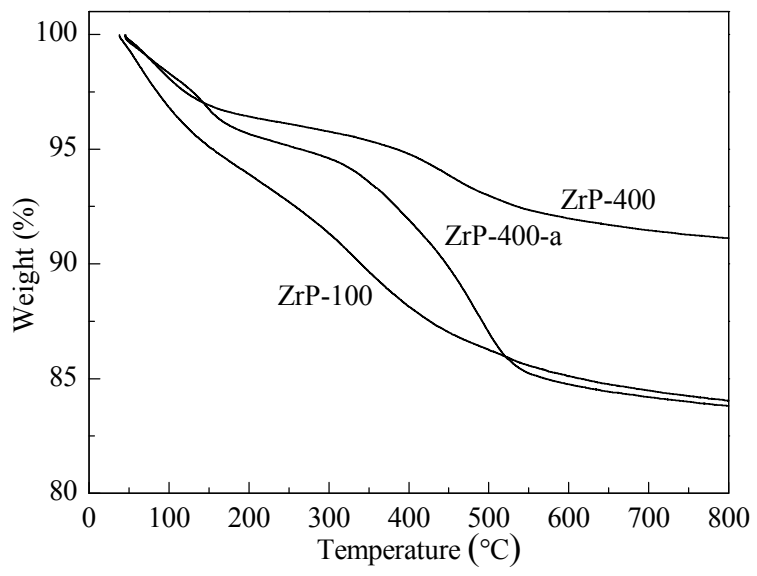

Fig. 2. TG curves of ZrP-100, ZrP-400, and the ZrP-400-a catalyst.

were obtained (Fig. 2). Dehydration led to a weight loss of ZrP-100 of $15.5 \%$ due to water removal from the catalyst. However, after calcination at $400{ }^{\circ} \mathrm{C}$ for $4 \mathrm{~h}$, it still exhibited a weight loss of $8 \%$, indicating that the $\mathrm{ZrP}-\mathrm{T}$ catalysts were hydrophilic.

The FT-IR spectra of ZrP-100 and ZrP-400 in Fig. 3 showed a weak peak at $755 \mathrm{~cm}^{-1}$ which was assigned to the P-O-P deforming vibration (poly phosphate), indicating the existence of the $\mathrm{P}-\mathrm{O}-\mathrm{P}$ bond. The transmission bands at $1000-1100 \mathrm{~cm}^{-1}$ corresponded to the $\mathrm{P}-\mathrm{O}$ stretching vibration, while the bands at 2400 and $525 \mathrm{~cm}^{-1}$ were due to the (P)-O-H stretching vibration and deformation vibration [38]. The bands at 3460 and $1626 \mathrm{~cm}^{-1}$ were attributed to the $\mathrm{OH}$ asymmetric stretching vibration, and the band at $1398 \mathrm{~cm}^{-1}$ corresponded to the bending mode of $\mathrm{OH}$ groups. These results were in agreement with those reported earlier [39]. These three bands became weaker after calcining at $400{ }^{\circ} \mathrm{C}$, demonstrating significant dehydration of the sample, which was in agreement with the TG results. Simultaneously, the bands of the P-O stretching region (1000-1100 $\mathrm{cm}^{-1}$ ) were shifted towards higher wavenumbers by $20 \mathrm{~cm}^{-1}$ as the calcination temperature was increased from 100 to $400{ }^{\circ} \mathrm{C}$, which indicated that the $\mathrm{P}-\mathrm{O}$ bonds in the tetrahedra became more covalent [36].

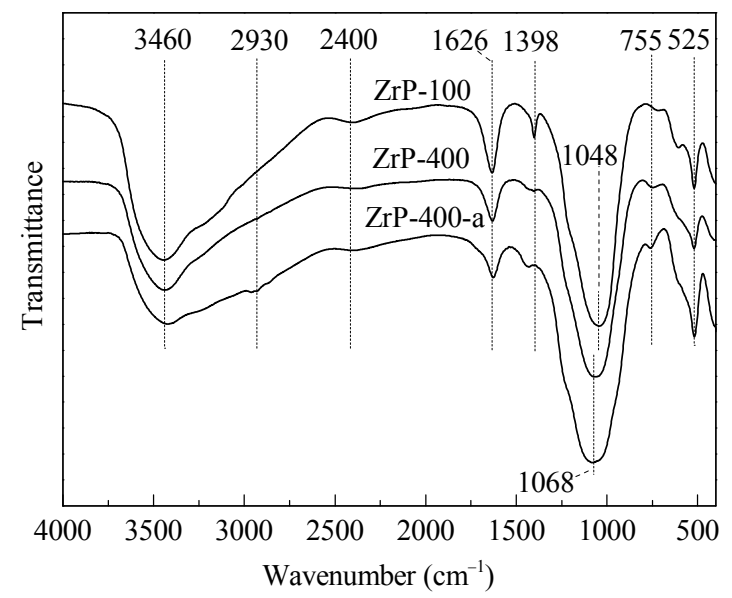

Fig. 3. FT-IR spectra of ZrP-100, ZrP-400, and the ZrP-400-a catalyst. 
In addition, the acidity of the catalysts was determined by titration with a solution of $n$-butylamine in cyclohexane using Hammett indicators [40]. All of the present samples did not show strong acid sites $\left(H_{0} \leq-8.2\right)$. As shown in Table 2, ZrP-HT, $\mathrm{ZrO}_{2}$, and $\mathrm{P} / \mathrm{ZrO}_{2}$ had only weak acid sites although the amounts of acid sites were quite different. For example, the total amount of acid sites in ZrP-HT was $0.93 \mathrm{mmol} / \mathrm{g}$, while $\mathrm{ZrO}_{2}$ has the least amount of acid sites, which was only 0.046 $\mathrm{mmol} / \mathrm{g}$. After impregnating of $\mathrm{ZrO}_{2}$ with $\mathrm{H}_{3} \mathrm{PO}_{4}$, the number of weak acid sites on the $\mathrm{P} / \mathrm{ZrO}_{2}$ catalyst increased greatly. However, the acid strength of the catalyst was still very weak. A reasonable explanation for this finding was that the doped phosphate acid condensed on the residual zirconium $\mathrm{OH}$ groups [41,42], resulting in no obvious changes in acid strength as compared with that of $\mathrm{ZrO}_{2}$. In contrast, it can be observed from Table 2 that all the $\mathrm{ZrP}-T$ samples showed both medium acidity strength $\left(-8.2<H_{0} \leq-3.0\right)$ and weak acid sites $(-3.0<$ $H_{0} \leq+6.8$ ). The fractional acidities of $\mathrm{ZrP}-\mathrm{T}$ at $-8.2<H_{0} \leq-3.0$ are also shown in the last column. Obviously, the total acidity decreased with the calcination temperatures (T). However, the fractional medium acidity increased with $T$ up to $400{ }^{\circ} \mathrm{C}$ and then decreased on further increase in $T$. The $\mathrm{ZrP}-400$ sample exhibited the largest medium strength acid ratio (44\%). The acidity enhancement could be due to an increased loss of weakly bonded water molecules during the calcination below $400{ }^{\circ} \mathrm{C}$, while the decline in acidity for the samples calcined at the higher $T$ (i.e., $T \geq 400{ }^{\circ} \mathrm{C}$ ) could be due to surface dehydroxylation. This $T$-dependent surface acidity for these $\mathrm{ZrP}-T$ sam- ples was similar to that of niobium oxide samples obtained by calcining $\mathrm{Nb}_{2} \mathrm{O}_{5} \cdot m \mathrm{H}_{2} \mathrm{O}$ [26] and $\mathrm{Ta}_{2} \mathrm{O}_{5} \cdot n \mathrm{H}_{2} \mathrm{O}$ [43]. The significantly higher fractional medium acidity at $-8.2<H_{0} \leq-3.0$ for the non-crystalline samples would indicate that the amorphous structure is important for the medium acidity distribution. The density of acid sites are also shown in the last column in Table 2. The acid densities of $\mathrm{P} / \mathrm{ZrO}_{2}$ and $\mathrm{ZrP}$-HT were very high, and $\mathrm{ZrO}_{2}$ has the lowest acid density, while the density of acid sites of $\mathrm{ZrP}-\mathrm{T}$ was relatively moderate and decreased with the increase of calcination temperature.

\subsection{Catalytic activity}

The catalytic activities for the gas phase dehydration of glycerol are given in Table 3. Acrolein and hydroxyacetone were the main products, while acetaldehyde, propanaldehyde, ethanol, and allyl alcohol were detected as minor side products. Other unidentified products also shown in Table 3 were possibly formed by secondary reactions of the products or the intermolecular condensation of glycerol, together with a very small amount of gaseous products such as CO, which possibly resulted from the decomposition of glycerol. Despite these unidentified products, the carbon balance was always over $70 \%$ except when $\mathrm{ZrO}_{2}$ was used as the catalyst. According to the results (Table 3), the $\mathrm{ZrO}_{2}, \mathrm{P} / \mathrm{ZrO}_{2}$, and $\mathrm{ZrP}$ - $\mathrm{HT}$ catalysts resulted in low and similar conversion of glycerol at 9-10 h time-on-stream, which were all less than $65 \%$. Combining these results with the acid properties of the catalyst surface (Table 2)

Table 2

Acid properties of the catalysts from $n$-butylamine titration.

\begin{tabular}{|c|c|c|c|c|c|}
\hline \multirow{2}{*}{ Catalyst } & \multicolumn{3}{|c|}{ Acid amount (mmol/g) } & \multirow{2}{*}{$\begin{array}{c}\text { Fraction acidity at } \\
-8.2<H_{0} \leq-3.0\end{array}$} & \multirow{2}{*}{$\begin{array}{l}\text { Acidity density } \\
\left(10^{-3} \mathrm{mmol} / \mathrm{m}^{2}\right)\end{array}$} \\
\hline & $-8.2<H_{0} \leq-3.0$ & $-3.0<H_{0} \leq+6.8$ & Total & & \\
\hline $\mathrm{ZrO}_{2}$ & 0 & 0.046 & 0.046 & 0 & 0.61 \\
\hline $\mathrm{P} / \mathrm{ZrO}_{2}$ & 0 & 0.19 & 0.19 & 0 & 47 \\
\hline ZrP-HT & 0 & 0.93 & 0.93 & 0 & 46 \\
\hline ZrP-100 & 0.56 & 1.0 & 1.56 & 0.36 & 13 \\
\hline $\mathrm{ZrP}-400$ & 0.45 & 0.58 & 1.03 & 0.44 & 10 \\
\hline ZrP-500 & 0.30 & 0.54 & 0.84 & 0.36 & 9.1 \\
\hline ZrP-600 & 0.14 & 0.32 & 0.46 & 0.30 & 5.8 \\
\hline ZrP-700 & 0.065 & 0.21 & 0.28 & 0.23 & 6.4 \\
\hline $\mathrm{ZrP}-400-\mathrm{b}$ & 0.068 & 0.70 & 0.77 & 0.088 & 9.4 \\
\hline
\end{tabular}

Table 3

Glycerol conversion and product selectivity over the different catalysts.

\begin{tabular}{|c|c|c|c|c|c|c|c|c|c|c|c|}
\hline \multirow{2}{*}{ Catalyst } & \multirow{2}{*}{$\begin{array}{c}\text { TOS a } \\
\text { (h) }\end{array}$} & \multirow{2}{*}{$\begin{array}{c}\text { Conversion } \\
(\%)\end{array}$} & \multirow{2}{*}{$\begin{array}{c}\text { Acrolein } \\
\text { yield (\%) }\end{array}$} & \multicolumn{7}{|c|}{ Product selectivity (\%) } & \multirow{2}{*}{$\begin{array}{c}\text { Carbon } \\
\text { balance }(\%)\end{array}$} \\
\hline & & & & Acrolein & Acetaldehyde & Propionaldehyde & Ethanol & Allyl alcohol & Acetol & Others & \\
\hline $\mathrm{ZrO}_{2}$ & 10 & 63.2 & 5.4 & 8.5 & 1.0 & 1.0 & 1.8 & 0.8 & 10.4 & 76.5 & 51.7 \\
\hline $\mathrm{P} / \mathrm{ZrO}_{2}$ & 10 & 52 & 18.1 & 34.9 & 0 & 0 & 1.1 & 0 & 8.4 & 56.4 & 70.7 \\
\hline ZrP-HT & 10 & 63.3 & 33.9 & 53.5 & 0.2 & 0.6 & 0.8 & 0.2 & 9.6 & 35.1 & 77.8 \\
\hline \multirow[t]{2}{*}{ ZrP-100 } & 10 & 100 & 70.9 & 70.9 & 0.6 & 1.6 & 0.5 & 0.4 & 10.3 & 15.7 & 84.3 \\
\hline & 24 & 87.8 & 64.8 & 73.9 & 0.5 & 1.5 & 0.3 & 0.4 & 12.6 & 10.8 & 89.2 \\
\hline \multirow[t]{2}{*}{$\mathrm{ZrP}-400$} & 10 & 100 & 81.5 & 81.5 & 1.0 & 1.9 & 0.2 & 0.4 & 11.2 & 3.8 & 96.2 \\
\hline & 24 & 93.6 & 76.4 & 81.7 & 0.7 & 1.7 & 0.2 & 0.4 & 11.3 & 3.2 & 96.8 \\
\hline \multirow[t]{2}{*}{ ZrP -500 } & 10 & 100 & 72.8 & 72.8 & 0.6 & 2.3 & 0.8 & 0.4 & 11.0 & 12.2 & 87.8 \\
\hline & 24 & 100 & 68.0 & 68.0 & 0.4 & 1.2 & 0.7 & 0.3 & 9.7 & 19.1 & 80.9 \\
\hline \multirow[t]{2}{*}{ ZrP -600 } & 10 & 100 & 66.6 & 66.6 & 0.8 & 2.7 & 0.6 & 0.6 & 10.3 & 18.4 & 81.6 \\
\hline & 24 & 100 & 64.3 & 64.3 & 0.6 & 2.0 & 0.9 & 0.5 & 10.4 & 21.2 & 78.8 \\
\hline \multirow[t]{2}{*}{$\mathrm{ZrP}-700$} & 10 & 100 & 63.4 & 63.4 & 0.8 & 2.6 & 0.6 & 0.6 & 9.9 & 22.1 & 77.9 \\
\hline & 24 & 100 & 62.2 & 62.2 & 0.6 & 2.0 & 0.5 & 0.5 & 9.7 & 24.5 & 75.5 \\
\hline
\end{tabular}

Reaction conditions: catalysts $0.5 \mathrm{~g}$, feed of $10 \mathrm{wt} \%$ glycerol in water, liquid flow $0.04 \mathrm{ml} / \mathrm{min}, \mathrm{N}_{2}$ flow $30 \mathrm{ml} / \mathrm{min}, 315^{\circ} \mathrm{C}$.

a The data at TOS $=10 \mathrm{~h}$ represents the average data between 9 and $10 \mathrm{~h}$, and the data at TOS $=24 \mathrm{~h}$ represents the average data between 23 and $24 \mathrm{~h}$. 
revealed that a high total amount of acid was not necessarily favorable for achieving a high conversion of glycerol. For these three catalysts, the obvious difference was the selectivity to acrolein, which decreased in the order $\mathrm{ZrP}-\mathrm{HT}>\mathrm{P} / \mathrm{ZrO}_{2}>\mathrm{ZrO}_{2}$. This order was consistent with the amounts of weak acidic sites (Table 2). In addition, previous studies $[44,45]$ have also shown that bulk $\mathrm{ZrO}_{2}$ gave a low selectivity to acrolein $(<10 \%)$ and also a commercial zirconia catalyst gave a glycerol conversion of $59 \%$ after 90 min TOS with an acrolein selectivity of $5 \%$ and hydroxyacetone selectivity of $25 \%$ [46]. Nevertheless, the complete conversion of glycerol was accomplished over the $\mathrm{ZrP}-\mathrm{T}$ catalysts within the first $10 \mathrm{~h}$ of reaction (Table 3). On the basis of these results, it can be deduced that amorphous zirconium phosphates gave a higher activity than the crystalline catalysts. This can be attributed to the defects on amorphous materials (ZrP-T), which provided more active sites (Fig. 1). In addition, it was found that the catalytic performance was closely correlated with the acid density. The $\mathrm{ZrO}_{2}$ catalyst with very low acid density (Table 2) showed very poor yield of acrolein at 9-10 h time-on-stream (Table 3). Although the $\mathrm{P} / \mathrm{ZrO}_{2}$ and $\mathrm{ZrP}-\mathrm{HT}$ catalysts had very high acid densities (Table 2), they exhibited only a slightly higher yield of acrolein than $\mathrm{ZrO}_{2}$ (Table 3). In contrast, the $\mathrm{ZrP}-T$ catalysts with a moderate acid density (Table 2) afforded a higher yield of acrolein (Table 3), and furthermore the acid density of the ZrP- $T$ catalysts decreased with the calcination temperature. Interestingly, ZrP-400 gave the highest yield of acrolein of all these catalysts. Thus these results indicated that both too high a density of acid sites and too low an acidity density were not favorable for a good performance by the catalyst. Obviously, a large specific surface area with an appropriate acidity density contributed to high catalytic efficiency. A large amount of water was adsorbed on $\mathrm{ZrP}-\mathrm{T}$, indicating that the surface of this catalyst was hydrophilic. Although a previous study has suggested that hydrophobicity of the catalyst surface is one of the main factors in the catalytic activity of acid-catalyzed reactions in the presence of water because the acid sites of most solid acids on a hydrophilic surface tended to be poisoned by water [47], the ZrP-T catalysts showed excellect activity for the reaction where water was present. This feature revealed that the relatively high surface area zirconium phosphate was highly water-tolerant, which may have resulted from that only limited acid sites were surrounded by a locally hydrophobic surface, or the acid sites of the zirconium phosphate had a specific structure that could avoid excessive attacks of water [48].

On the other hand, the weak acid catalysts with acid strength at $-3.0<H_{0} \leq+6.8$ (Table $2, \mathrm{ZrO}_{2}, \mathrm{P} / \mathrm{ZrO}_{2}$, and $\mathrm{ZrP}-\mathrm{HT}$ ), showed a low conversion of glycerol and low selectivity for the production of acrolein, while the catalysts which have a medium acid strength at $-8.2<H_{0} \leq-3.0$ (Table 2 , ZrP- $T$ ) generally showed a high glycerol conversion and high acrolein selectivity. This implied that the most effective acid strength for the dehydration of glycerol to form acrolein was $-8.2<H_{0} \leq-3.0$. The selectivity to the main byproduct acetol was not affected by the amount of acid or the acid strength of the catalyst. An attempt was carried out to correlate the selectivity to acrolein at TOS = 9-10 h over the ZrP-T catalysts with the fractional acidity at
$-8.2<H_{0} \leq-3.0$. The correlation of acrolein selectivity and fractional acidity at $-8.2<H_{0} \leq-3.0$ is presented in Fig. 4 . It can be seen clearly that the selectivity to acrolein increased with the increasing of the fractional medium strength acidity at $-8.2<$ $H_{0} \leq-3.0$.

The ZrP-400 catalyst afforded 81\% yield of acrolein, which was slightly better than the catalysts calcined at other temperatures when the TOS was 9-10 h (Table 3). In addition, it was found that the $\mathrm{ZrP}-\mathrm{T}$ catalysts only showed slight deactivation when the TOS was prolonged to $24 \mathrm{~h}$, which could be due to the fact that phosphate stabilized the amorphous zirconia phase, which gave the $\mathrm{ZrP}-T$ catalyst a relatively stable catalytic activity [49]. Because ZrP-400 exhibited the best activity, the used $\mathrm{ZrP}-\mathrm{T}$ catalyst was characterized to understand the reason for deactivation because catalyst deactivation is an important factor for most catalysts in the glycerol dehydration reaction. As shown in Fig. 1(b), after ZrP-400 was subjected to reaction for $24 \mathrm{~h}$, the catalyst still remained amorphous. However, the BET surface area was decreased sharply from 101 to $28 \mathrm{~m}^{2} / \mathrm{g}$, and the weight loss of ZrP-400 was significantly increased (Fig. 2). The weight loss may result from carbonaceous sediments as well as the incorporation of a small amount of water during the reaction. In the IR spectra in Fig. 3, a new peak appeared at $2930 \mathrm{~cm}^{-1}$ with the used $\mathrm{ZrP}-400$ catalyst, which was assigned to $-\mathrm{CH}_{2}-$ asymmetry stretching vibration, indicating that the oligomerization of glycerol or nonsaturated products like acrolein was a possible route for these deposits. From the comparison of fresh ZrP-400 and used ZrP-400 above, we can infer that the carbonaceous material deposited on the catalyst surface caused the decrease in the specific surface area and reduced the contact of the substrate with active sites, which led to a decrease in catalyst activity. It should be noted that although $\mathrm{ZrP}-\mathrm{T}$ calcined at 500,600 , and $700{ }^{\circ} \mathrm{C}$ maintained a glycerol conversion of $100 \%$ at long reaction time (TOS $=23-24 \mathrm{~h}$ ), their selectivities to acrolein were lower than 70\%. ZrP-400 was still the most selective catalyst for acrolein with a value of $81.7 \%$.

Next, the ZrP-400 catalyst was used to examine the effect of temperature on catalytic performance. As shown in Fig. 5, the glycerol conversion increased with reaction temperatures, and this was maintained at $100 \%$ at above $300{ }^{\circ} \mathrm{C}$. Previous studies [50] have stated that temperatures lower than $280{ }^{\circ} \mathrm{C}$ favored

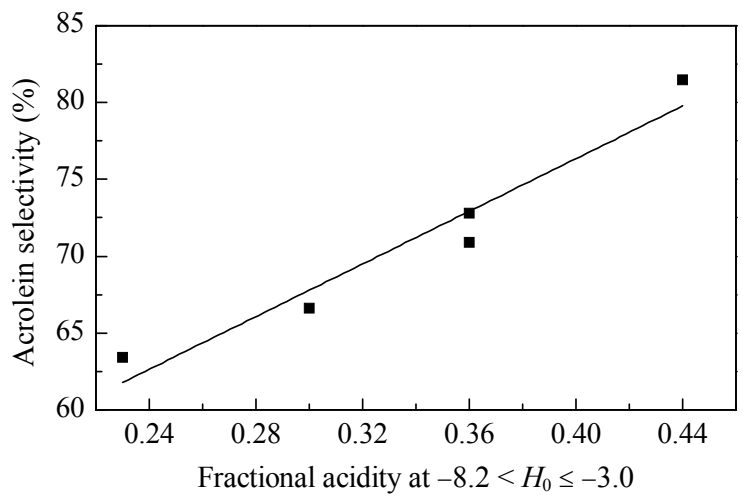

Fig. 4. Correlation between fractional acidity at $-8.2<H_{0} \leq-3.0$ for $\mathrm{ZrP}-\mathrm{T}$ samples and the selectivity for acrolein at TOS $=9-10 \mathrm{~h}$. 


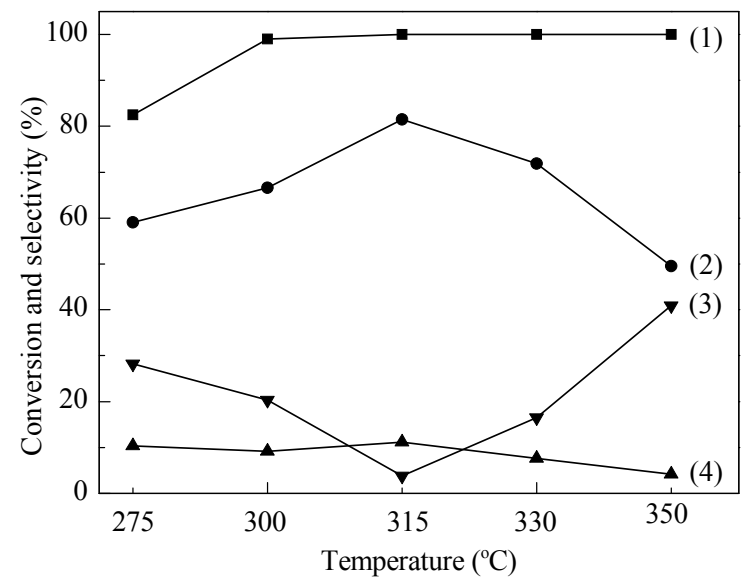

Fig. 5. Product selectivities and conversion of glycerol from glycerol (10 wt\%) dehydration over the ZrP-400 catalyst at different reaction temperatures. TOS = 9-10 h. (1) Glycerol conversion; (2) Selectivity for acrolein; (3) Selectivity for other products; (4) Selectivity for acetol.

the intermolecular dehydration of glycerol (b.p. $290^{\circ} \mathrm{C}$ ) on the catalyst surface, which led to glycerol oligomers instead of to acrolein. Therefore, the formation of oligomers was responsible for the low acrolein selectivity at lower temperatures. The acrolein yield increased with the reaction temperatures in the range from $275^{\circ} \mathrm{C}$ to $315^{\circ} \mathrm{C}$, and the maximum yield reached $81 \mathrm{~mol} \%$ at $315{ }^{\circ} \mathrm{C}$. However, the yield of acrolein decreased sharply above $315^{\circ} \mathrm{C}$, which can be attributed to the deposition of carbonaceous material and the condensation of reaction products at higher temperature [51].

The ZrP-400 catalyst was also checked for long-term performance to evaluate its deactivation. The conversion and selectivity versus time are shown in Fig. 6(a). The initial conversion of glycerol was $100 \%$, but this decreased rapidly to $74 \%$ within $48 \mathrm{~h}$ on stream. The stability and selectivity to acrolein over the present zirconium phosphate catalysts were still comparable to the previously reported metal phosphates [20-24]. Actually, the product distribution did not show any significant change during the $48 \mathrm{~h}$. The used catalyst showed a dark color, indicating the presence of a considerable amount of carbonaceous deposits on the surface of catalyst. This behavior pointed to a deactivation mechanism due to carbonaceous deposits blocking the catalytically active sites. At the same time, a slight decrease of acrolein selectivity was observed. The catalyst after reaction for $48 \mathrm{~h}$ was dried in situ under a carrier gas stream, and then taken out and calcined at $500{ }^{\circ} \mathrm{C}$ in a muffle furnace for $4 \mathrm{~h}$. After that, it was subjected to the determination of its specific surface area and $n$-butylamine titration. The specific surface area of the regenerated catalyst was $82 \mathrm{~m}^{2} / \mathrm{g}$, which was close to that of the fresh $\mathrm{ZrP}-500$ (92 $\left.\mathrm{m}^{2} / \mathrm{g}\right)$. The determination of acidity by $n$-butylamine titration showed that the medium strength acid sites have decreased dramatically (Table 2, ZrP-400-b), which led to the decrease of the total amount of acid as compared with the fresh catalyst. In addition, the elemental analysis by AES-ICP demonstrated that the mass contents of $\mathrm{P}$ and $\mathrm{Zr}$ did not show any obvious change after the catalyst had reacted for $48 \mathrm{~h}$, indicating that the leaching of $\mathrm{P}$ and $\mathrm{Zr}$ was not a cause of the catalyst deactivation. We can infer

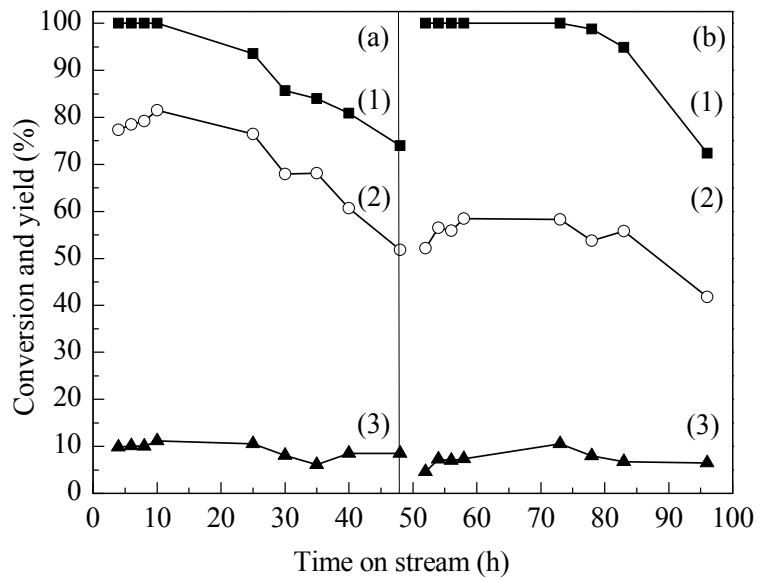

Fig. 6. Time course of glycerol conversion and product yield. (a) The conversion of glycerol was carried out for $48 \mathrm{~h}$ on-stream; (b) After reaction for $48 \mathrm{~h}$, the catalyst was regenerated by calcining at $500{ }^{\circ} \mathrm{C}$ for $4 \mathrm{~h}$ and then reused for reaction for another $48 \mathrm{~h}$; (1) Glycerol conversion; (2) Yield of acrolein; (3) Yield of acetol.

that on one hand the carbonaceous deposits on the surface of catalyst reduced the number of accessible active sites, and on the other hand the medium strength acid sites on the catalyst surface were reduced considerably during the reaction, and both of these led to a decrease in the yield of acrolein. A regenerated catalyst from the calcining of the used catalyst (after 48 $\mathrm{h}$ reaction) at $500{ }^{\circ} \mathrm{C}$ for $4 \mathrm{~h}$ was reused in the reaction in the fixed-bed reactor under the same reaction condition as before. The conversion was recovered to $100 \%$ and the selectivity to acrolein reached 58\% during the initial $10 \mathrm{~h}$ (Fig. 6(b)). After reaction for $48 \mathrm{~h}$, the conversion of glycerol was reduced to $72 \%$. This experiment indicated that the recovery of catalytic activity is possible by calcining the spent catalyst in air.

\section{Conclusions}

Zirconium phosphate catalysts prepared by different methods have differences not only in texture but also in the surface acidity of the catalyst. The catalytic performance for the dehydration of glycerol was significantly affected by the preparation method and calcination temperature. Amorphous zirconium phosphates obtained by the precipitation method have medium strength and weak acidity, and they were highly selective catalysts for acrolein production (yield 62\%-82\%) in the gas phase dehydration of glycerol. The amorphous catalyst obtained by calcination at $400{ }^{\circ} \mathrm{C}(\mathrm{ZrP}-400)$ exhibited the largest fraction of medium strength acid sites at $-8.2<H_{0} \leq-3.0$ and had the best catalytic efficiency for the formation of acrolein, which indicated that an appropriate amount of acid sites and acid strength was favorable for catalyst stability. A simple regeneration procedure by calcining the used catalyst in air was sufficient to regenerate the deactivated catalysts to its original activity, although there was a slight decrease in the production of acrolein.

\section{References}

[1] Ng J H, Ng H K, Gan S. Clean Technol Environol Policy, 2010, 12: 459 


\section{Graphical Abstract}

Chin. J. Catal., 2014, 35: 1148-1156 doi: 10.1016/S1872-2067(14)60057-7

\section{Gas phase dehydration of glycerol to acrolein catalyzed by zirconium phosphate}

Huimei Gan, Xiuge Zhao, Baoning Song, Li Guo, Ran Zhang, Chen Chen, Jizhong Chen, Wenwen Zhu, Zhenshan Hou* East China University of Science and Technology

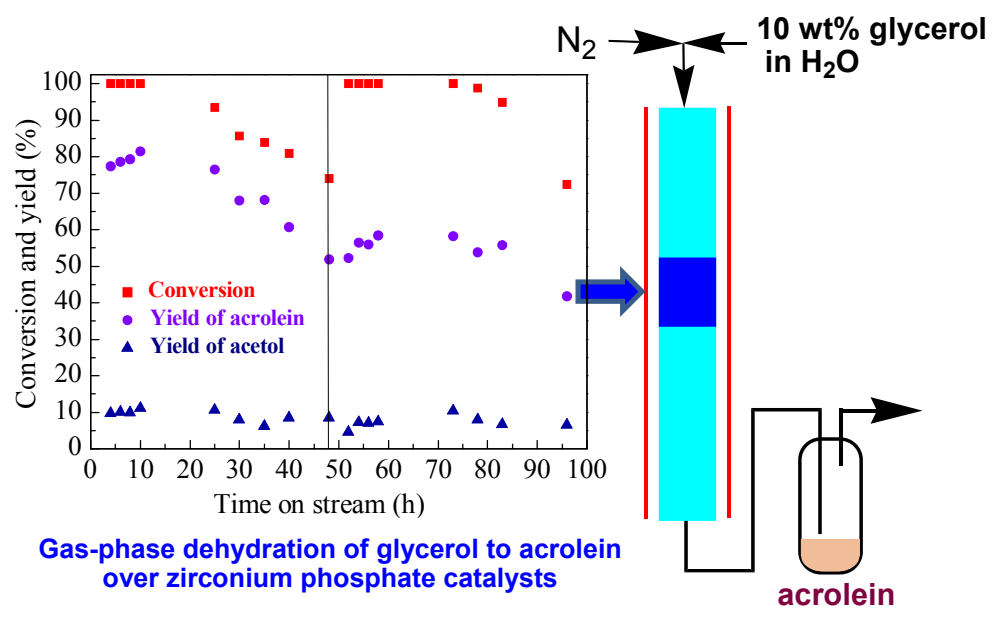

Zirconium phosphates prepared by three different methods were used for the gas phase dehydration of glycerol under mild reaction conditions.

[2] Atabani A E, Silitonga A S, Ong H C, Mahlia T M I, Masjuki H H, Badruddin I A, Fayaz H. Renew Sustain Energy Rev, 2013, 18: 211

[3] Beatrice C, Blasio G D, Lazzaro M, Cannilla C, Bonura G, Frusteri F, Asdrubali F, Baldinelli G, Presciutti A, Fantozzi F, Bidini G, Bartocci P. Appl Energy, 2013, 102: 63

[4] Dubois J L. US Patent 20120283479. 2012

[5] Katryniok B, Paul S, Dumeignil F. ACS Catal, 2013, 3: 1819

[6] Bühler W, Dinjus E, Ederer H J, Kruse A, Mas C. J Supercrit Fluids, 2002, 22: 37

[7] Watanabe M, Iida T, Aizawa Y, Aida T M, Inomata H. Bioresour Technol, 2007, 98: 1285

[8] Lehr V, Sarlea M, Ott L, Vogel H. Catal Today, 2007, 121: 121

[9] Tsukuda E, Sato S, Takahashi R, Sodesawa T. Catal Commun, 2007, 8: 1349

[10] Ning L L, Ding Y J, Chen W M, Gong L F, Lin R H, Lü Y, Xin Q. Chin J Catal (宁丽丽, 丁云杰, 陈维苗, 龚否峰, 林荣和, 吕元, 辛勤. 催 化学报), 2008, 29: 212

[11] Chai S H, Wang H P, Liang Y, Xu B Q. Appl Catal A, 2009, 353: 213

[12] Shen L Q, Feng Y H, Yin H B, Wang A L, Yu L B, Jiang T S, Shen Y T, Wu Z A.J Ind Eng Chem, 2011, 17: 484

[13] Liu R, Wang T F, Liu C, Jin Y. Chin J Catal (刘蓉, 王铁峰, 刘畅, 金涌. 催化学报), 2013, 34: 2174

[14] Ulgen A, Hoelderich W. Catal Lett, 2009, 131:122

[15] Ulgen A, Hoelderich W. Appl Catal A, 2011, 400: 34

[16] Lauriol-Garbay P, Millet J M M, Loridant S, Bellière-Baca V, Rey P.J Catal, 2011, 280: 68

[17] Corma A, Huber G W, Sauvanaud L, O'Connor P. J Catal, 2008, 257: 163

[18] Kim Y T, Jung K D, Park E D. Appl Catal A, 2011, 393: 275

[19] Lourenco J P, Macedo M I, Fernandes A. Catal Commun, 2012, 19: 105

[20] Wang F, Dubois J L, Ueda W. J Catal, 2009, 268: 260

[21] Wang F, Dubois J L, Ueda W. Appl Catal A, 2010, 376: 25
[22] Deleplanque J, Dubois J L, Devaux J F, Ueda W. Catal Today, 2010, 157: 351

[23] Suprun W, Lutecki M, Gläser R, Papp H. J Mol Catal A, 2011, 342-343: 91

[24] Pethan Rajan N, Rao G S, Pavankumar V, Chary K V R. Catal Sci Technol, 2014, 4: 81

[25] Haider M H, Dummer N F, Zhang D Z, Miedziak P, Davies T E, Taylor S H, Willock D J, Knight D W, Chadwick D, Hutchings G J. J Catal, 2012, 286: 206

[26] Chai S H, Wang H P, Liang Y, Xu B Q. J Catal, 2007, 250: 342

[27] Alhanash A, Kozhevnikova E F, Kozhevnikov I V. Appl Catal A, 2010, 378: 11

[28] Sinhamahapatra A, Sutradhar N, Roy B, Pal P, Bajaj H C, Panda A B. Appl Catal B, 2011, 103: 378

[29] Das S K, Bhunia M K, Sinha A K, Bhaumik A. ACS Catal, 2011, 1: 493

[30] Khare S, Chokhare R. J Mol Catal A, 2011, 344: 83

[31] Weingarten R, Kim Y T, Tompsett G A, Fernández A, Han K S, Hagaman E W, Conner W C Jr, Dumesic J A, Huber G W. J Catal, 2013, 304: 123

[32] Ordomsky V V, Sushkevich V L, Schouten J C, van der Schaaf J, Nijhuis T A. J Catal, 2013, 300: 37

[33] Cui H, Li Q, Gao S, Shang J K.J Ind Eng Chem, 2012, 18: 1418

[34] Burnell V A, Readman J E, Tang C C, Parker J E, Thompson S P, Hriljac J A.J Solid State Chem, 2010, 183: 2196

[35] Sinhamahapatra A, Sutradhar N, Roy B, Tarafdar A, Bajaj H C, Panda A B. Appl Catal A, 2010, 385: 22

[36] Weingarten R, Tompsett G A, Conner W C Jr, Huber G W. J Catal, 2011, 279: 174

[37] Ramesh K, Hui L M, Han Y F, Borgna A. Catal Commun, 2009, 10: 567

[38] Miao Z C, Xu L L, Song H L, Zhao H H, Chou L J. Catal Sci Technol, 2013, 3: 1942

[39] Mao H H, Lu X H, Li M S, Yang J H, Li B S. Appl Surf Sci, 2013, 276: 
787

[40] Chai S H, Wang H P, Liang Y, Xu B Q. Green Chem, 2007, 9: 1130

[41] Ikeda Y, Asadullah M, Fujimoto K, Tomishige K. J Phys Chem B, 2001, 105: 10653

[42] Xue N H, Chen X K, Nie L, Guo X F, Ding W P, Chen Y, Gu M, Xie Z K. J Catal, 2007, 248: 20

[43] Tao L Z, Yan B, Liang Y, Xu B Q. Green Chem, 2013, 15: 696

[44] Chai S H, Wang H P, Liang Y, Xu B Q. Green Chem, 2008, 10: 1087

[45] Tao L Z, Chai S H, Zuo Y, Zheng W T, Liang Y, Xu B Q. Catal Today, 2010, 158: 310

[46] Stosic D, Bennici S, Couturier J L, Dubois J L, Auroux A. Catal
Commun, 2012, 17: 23

[47] Okuhara T. Chem Rev, 2002, 102: 3641

[48] Kamiya Y, Sakata S, Yoshinaga Y, Ohnishi R, Okuharaa T. Catal Lett, 2004, 94: 45

[49] Weingarten R, Kim Y T, Tompsett G A, Fernández A, Han K S, Hagaman E W, Conner W C Jr, Dumesic J A, Huber G W. J Catal, 2013, 304: 123

[50] Ulgen A, Hoelderich W F. Appl Catal A, 2011, 400: 34

[51] Garcia-Sancho C, Moreno-Tost R, Merida-Robles J, SantamariaGonzález J, Jimenez-López A, Maireless-Torres P. Appl Catal A, 2012, 433-434: 179

\section{磷酸锆催化甘油气相脱水制备丙烯醛}

干慧媚, 赵秀阁, 宋宝宁, 郭立, 张 然, 陈晨, 陈吉忠, 朱闻闻, 侯震山* 华东理工大学工业催化研究所，结构可控先进功能材料及其制备教育部重点实验室，上海200237

摘要: 以沉淀法、水热合成法和浸渍法制备了磷酸铅催化剂, 通过X射线衍射、热重分析、氮气物理吸附、红外光谱和Hammett 指示剂法对催化剂进行了表征, 并将该催化剂用于甘油气相脱水反应. 研究表明, 由沉淀法得到的磷酸铅经过 $400{ }^{\circ} \mathrm{C}$ 焙烧后能达 到最佳催化活性, 在温和条件下, 甘油可完全转化, 丙烯醛选择性为 $81 \%$, 反应 $24 \mathrm{~h}$ 内催化剂失活不明显. 不同方法制备的磷酸铅 其结构和表面酸性显著不同, 催化剂表面酸性对催化剂活性、丙烯醛选择性和催化剂的寿命均有较大影响.

关键词: 甘油; 脱水; 丙烯醛; 磷酸钻; 酸性

收稿日期: 2013-12-20. 接受日期: 2014-02-20. 出版日期: 2014-07-20.

*通讯联系人. 电话: (021)64251686; 传真: (021)64253372; 电子信箱: houzhenshan@ecust.edu.cn

基金来源：国家自然科学基金(U1179302, 21373082, 21073058); 高等学校博士学科点专项科研基金(20100074110014); 中央高校 基本科研业务费专项资金.

本文的英文电子版由Elsevier出版社在ScienceDirect上出版(http://www.sciencedirect.com/science/journal/18722067). 